\title{
HEPA Promotion in the Environment of Academic Scientists - Preliminary Research
}

Authors' contribution:
A) conception and design of the study
B) acquisition of data
C) analysis and interpretation of data
D) manuscript preparation
E) obtaining funding

\author{
Wojciech J. Cynarski ${ }^{1 \mathrm{~A}, \mathrm{C}, \mathrm{D}, \mathrm{E}}$, Renata Grzywacz ${ }^{1 \mathrm{~A}, \mathrm{D}}$, \\ Krzysztof Kubala $^{1 \mathrm{~B}}$, Magdalena Kunysz-Rozborska ${ }^{1 \mathrm{~B}}$, \\ Adam Podolski ${ }^{1 \mathrm{~B}}$, Przemysław Pawelec ${ }^{2 \mathrm{C}}$ \\ ${ }^{1}$ University of Rzeszow, Poland \\ ${ }^{2}$ Idokan Poland Association, Poland
}

\section{ABSTRACT}

\begin{abstract}
The theoretical framework for this research is the sociology of leisure and the sociology of health. Because sedentary behaviour (of employees) is a relevant new research area with important health risks, we decided to focus our attention on this subject. Moreover, sedentary behaviour in the workplace seems to be an important topic for the future.

The general aim of the research is to provide a platform for exchange on effective approaches for promoting health-enhancing physical activity among workers, to learn from experiences in different European countries and to promote the most effective approaches across Europe.

Two methods of qualitative research were used. The first was the method of expert judges. By way of direct interview, the statements of nine persons were collected, all of whom were recognised as competent judges. The second method was the analysis of the content of the literature (quality method). Using the computer program Atlas.ti, the respondents and their answers were examined.

Most of the indications (89\%) concerned responses indicating physical activity. In general, the experts are quite physically active and keep a healthy (in their opinion) diet. They have both knowledge and appropriate skills in physical education. They point to the growing interest of younger academics in health and fitness, which may be associated with trends in popular culture, such as a sporty lifestyle, the cult of the body, various healthy diets and supplements, etc., that are becoming the universal fashion.

The aim of this work was to provide a platform for exchange on effective approaches to the promotion of health-enhancing physical activity among workers, to learn from experience in different European countries and to promote the most effective approaches across the region. Because the sedentary behaviour of employees is a relevant new research area with important health risks, we decided to focus our attention on this subject. health, health promotion, prevention
\end{abstract}

KEYWORDS

\section{Introduction}

HEPA Europe (European Network for the Promotion of Health-Enhancing Physical Activity) is a European organization directly under the World Health Organization (original name: World Health Organization - Regional Office for Europe). Its purpose is to improve health on the basis of broad physical 
activity. The organization deals with the research and publication of scholarly materials in the field of health education and health promotion, benchmarking studies among international organizations and the organization of international conferences involving international experts in the field of health and physical activity. HEPA Europe has 126 members, including the following: the University of Graz Institute of Sports Science, Austria; the International Physical Activity and the Environment Network (IPEN), Ghent University, Belgium; the Public Health Directorate Ministry of Health, Bulgaria; Croatian Sports Medicine Society, University of Zagreb, the National Centre for Health Promotion and Disease Prevention; the National Board of Health, Denmark; the Ministry of Social Affairs and Health, Finland; the Faculty of Sport, Nancy University, France; the Department of Prevention and Health Promotion, University of Bielefeld, Germany ${ }^{1}$.

The workplace HEPA promotion working group was led by Ms Ingrid Hendriksen from the Netherlands Organization for Applied Scientific Research (TNO) and Mr Hans Arends (NISB). The purpose of the session was to discuss ideas on cooperation on the identified focus theme of the working group, namely "sedentary behaviour in the workplace". A questionnaire had previously been sent to the working group to collect information on their current activities regarding sedentary behaviour in each country. Responses received from several working group members representing four European countries were presented (Denmark, Finland, the Netherlands and the United Kingdom) ${ }^{2}$. Health education and health promotion, with a focus on physical activity, is HEPA's main area of interest. Promotional activities to promote health (proper diet, physical activity, relaxation, etc.) first require a diagnosis of the current state of health. The purpose of the preliminary phase of the research is to identify the state of knowledge and attitudes to health research in work environments, academic environments and selected scientific societies. I mean especially an analysis of attitudes towards the health of the leaders of the scientific community.

\section{Material and methods}

Two methods of qualitative research were used. The first was the method of expert judges. By way of direct interview, the statements of nine persons were collected, all of whom were recognised as competent judges. These included the deans of the faculties of physical education and pedagogy at universities and leaders of physical culture, physical education and sport studies. The tool used was a short questionnaire including the following questions:

1. What are your favourite and most frequently used forms of leisure? Where do you participate in physical activity, and what is the form of this activity? How often do you participate in physical activity?

2. How do you take care of your health? Is it relative to other needs and values?

3. How do you evaluate your knowledge regarding the health risk factors of diet and lifestyle?

4. How do you evaluate the attitude towards health in the working environment at universities, in various scientific institutions and in the academic community?

The second method was the analysis of the content of the literature (quality method) (Krippendorf, 2004; Mayring, 2004). Publications were also included concerning the promotion of this institution and the above values in scientific environments (universities, research societies). The studies relate mainly to Rzeszow University and other colleges/ universities of Rzeszow, where physical education and sport is significant, as well as several scientific societies: EASS (European Association for Sociology of Sport), IPA (Idokan Poland Association), ISSSS (International Society for Social Sciences of Sport), IMACSSS (International Martial Arts and Combat Sports Scientific Society) and IASK (International Association of Sport Kinetics).

\footnotetext{
${ }^{1}$ HEPA EUROPE European network for the promotion of health-enhancing physical activity, World Health Organization - regional office for Europe, Report of Work Programme 2013/14.

${ }^{2}$ Report of a WHO meeting 23-24 October 2013, Helsinki, Finland.
} 


\section{Results}

The promotion of HEPA activity took place in the environment of the University of Rzeszow through the publication of articles of several popular works of that organization on the pages of The University Journal for Staff and Students (Grzywacz, \& Wielgos, 2013; Cynarski, 2014a). In addition, the above content for EASS and other scientific societies was published in the quarterly Ido Movement for Culture. Journal of Martial Arts Anthropology (Cynarski, \& Duriček, 2014). Because it is a periodical published by the IPA under the auspices of two other international scientific societies (IMACSSS and IASK), one can expect that the content of HEPA was delivered to a wide audience. Outside the scientific societies, HEPA promotes a healthy lifestyle, positive values of physical culture, a culture of health and an active lifestyle. It concerns the ideal man - active and creative, healthy and highly educated (Cynarski, 2009; Sieber, Litwiniuk, \& Cynarski, 2010; Boguszewski et al., 2014). In terms of active leisure, etc., it particularly concerns IPA and IMACSSS (Status IMACSSS; Status IPA; cf. Cynarski, \& Yu, 2011; Zeng, Cynarski, \& Xie, 2013).

Using the computer program Atlas.ti, the respondents and their answers were examined (answers from the first to the third questions, as those directly concerned physical activity). The image found in Figure 1 provides the differentiation of the answers.

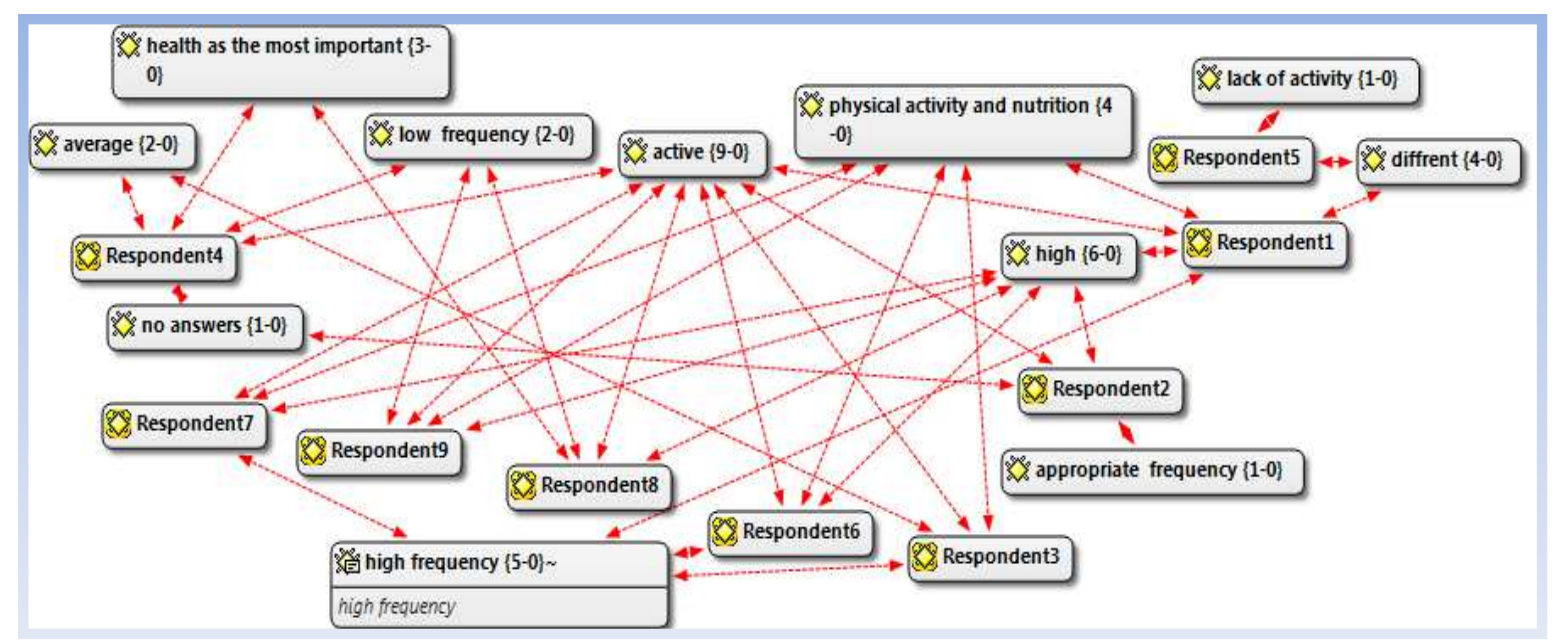

Figure 1. The correlation between the respondents and their answers Source: own study.

According to the information in the title of the chart, the average variation among the respondents in the responses is provided. The fact that none of the categories were selected by all of the respondents is important. However, there are categories that were identified only by one person. Most of the indications (9) concerned the response indicating physical activity (Question 1). In a few cases, some of the categories were not selected, and thus did not appear on the chart. The first respondent (as can be seen on the graph) shows a high frequency of activity. He eats a healthy diet and treats his health and other needs seriously. In addition, he highly evaluates his knowledge concerning health care.

The second respondent also spends his time actively, but participates in physical activity less frequently (once a week). He also eats a healthy diet, preferring healthy nutrition. He highly evaluates his knowledge of health, but does not provide an answer to the question about its relationship to other needs and values. The third of the surveyed persons works actively (using motor activity and healthy eating) with a high frequency. His health is valued as high as other needs; however, he identifies his level of knowledge about it as medium.

Compared with the previous person, the fourth respondent declares a low frequency of activity. However, he claims that his level of knowledge about health is at the same level (medium), which is one of the highest values. In the fifth case, the respondent declares a lack of time and activity in caring for his own health. This person also has problems with the level of available information on health topics. The sixth and seventh 
respondents are characterized by high physical activity, which is connected with taking care of proper nutrition. In their cases, the high frequency of physical activity correlates with the stated high level of expertise on health subjects. However, the eighth and ninth respondents, who rarely undertake any physical activity, claim to value their health equally with other needs of life.

An analysis of the expression of these competent judges allows us to notice certain trends and patterns. Eight out of nine of the interviewed persons declared that they regularly engage in physical activity. In this case, the frequency of physical activity is from never to everyday; in five of the cases (55\% expression), the judges claimed to engage in activity at least five times a week. Forms of this activity are diverse: running, walking, swimming, cycling, tennis, skiing and sometimes also other forms of fitness such as football, water sports, etc. One person acknowledged the utter lack of time for this kind of activity. Other forms of recreation or leisure time activity mentioned were music and theatre.

One person did not attach any particular importance to this kind of activity (physical, leisure time) or to their own health care. Others confirmed or declared that they care for their health. Respondent number four stated that health is a value that enables the implementation of other values. Expert number one replied that he cares, but this was an exaggeration. For one respondent, it was even the most important value. Six respondents confirmed that they care for their health by following a proper diet, and seven do so through physical activity. One expert pointed to the implementation of yearly check-ups.

The experts confirmed the possession of knowledge and awareness regarding health and risk factors of civilization diseases at a high level in seven cases (78\%). However, only one claimed to apply this knowledge in practice in life and with family. On the other hand, the answer to the first question implicitly suggests that almost all of our experts participate in the culture of health and physical activity.

On the other hand, how do the men of science assess physical activity in the academic environment? Expert number six gives a rather negative assessment: “... based on observation and experience, resulting from long work as a teacher in physical education, physical culture and scientific knowledge regarding the health of the Polish and the level of health awareness, as well as the general level of physical activity of the average Polish person, despite the positive changes taking place among some of the younger generation, I must acknowledge the attitude of the vast part of the environment to health as low and requiring decisive reevaluation".

Judge nine points to weak activity in academia outside of the science of physical culture, which is more conscious and physically active. Also, judge number two suggests that the representatives of physical education are more active. In turn, expert number one gives a statement that is ambivalent in its assessment. Expert number three notes that pharmacology is often seen by people as a source of health, rather than taking care of their own body through exercise. Meanwhile, the minority cares about hardening the organism and efficiency. Judge number five notes positive changes in health care and the awareness of the risks of disease. Expert number seven sees generational change - younger academics care more about health: “ $\ldots$ the younger generations of teachers already care about their health and physical activity and are convinced of the activities in this field, in significant part. I think it is related to the fact that they have children and try to spend time with them actively, giving them certain habits to be healthier. In contrast, the older generation does not have colleagues with this knowledge and these habits, and physical activity is beginning to be used only when they are referred by doctors for rehabilitation".

Judge number eight indicates an increase in physical activity both in teachers and students. He sees it positively, like expert number four, who stated the following: "Attitudes towards health, in my opinion, are a positive transformation. Many people whom you talk to highlight the growing role of health in a society that has a fast pace of life. We are increasingly sensing how much value is in health care and caring about a healthy lifestyle. I will gladly support those who promote health care and sport". 


\section{Discussion}

The attention to physical fitness, as well as hardening the organism to changes in temperature and other factors, appears to be satisfactory only among the representatives of physical education. These are positive indicators for the potential of health care. Does the Polish scientific community not know about the achievements of Poland in the development of the theory of physical education (cf. Cynarski, 2014b)? Studies of physical activity rarely mention relaxation. Exercises from other cultures are typically not preferred here. These exercises include yoga and qigong, different methods of breathing exercises, meditation, centring and energizing (Moegling, 2006).

In general, experts are themselves quite active physically and keep a healthy (in their opinion) diet. They have both knowledge and appropriate skills in physical education. They point to the growing interest of younger academics in health and fitness, which may be associated with trends in popular culture, such as a sporty lifestyle, the cult of the body, various healthy diets and supplements, etc., that are becoming the universal fashion. Everyone seems to be quite optimistic.

Generally speaking, academic physical education in Poland does not deviate significantly from that practiced in Western Europe. The state is also significantly better than, for instance, in the neighbouring country of Belarus (Cavill, Kahlmeier, \& Racioppi, 2006; Uher, 2009; Łukiewicz, 2013; Cynarski et al., 2014). This doesn't mean, however, that activities to promote healthy activity in the academic community are unnecessary.

Mass sports events (sport for all, sport the whole family, sport for life), especially cross country skiing, and the combination of active rest with the medical justification for a healthy lifestyle have become part of the academic calendar of events (Junger, 2009; Zadarko, \& Barabasz, 2009).

\section{Conclusions}

Physical activity is one of the most basic human functions. According to the report of a WHO meeting, sedentary behaviour in the workplace seems to be an important topic for the future. All attendees, including the Faculty of Physical Education of the University of Rzeszow, expressed the wish to be involved in further initiatives and to make a contribution.

The aim of this work was to provide a platform for exchange on effective approaches for promoting health-enhancing physical activity among workers, to learn from experience in different European countries and to promote the most effective approaches across the region. Because the sedentary behaviour of employees is a relevant new research area with important health risks, it was decided that we would focus our attention on this subject.

\section{REFERENCES}

Boguszewski, D., Adamczyk, J.G., Suchcicka, B., Słyk, E., \& Białoszewski, D. (2014). The estimation of health-related behaviours of men practising aikido and capoeira. Ido Movement for Culture. Journal of Martial Arts Anthropology, 2 , 41-46. DOI: 10.14589/ido.14.2.6.

Cavill, N., Kahlmeier, S., \& Racioppi, F. (Eds.) (2006). Physical activity and health in Europe: evidence for action. Kopenhagen: WHO Europe.

Cynarski, W.J. (2009). Martial Arts - Ido \& Idokan. Rzeszow: IPA.

Cynarski, W.J. (2014a). O XI Konferencji i Kongresie Europejskiego Stowarzyszenia Socjologów Sportu w Utrechcie /About the $9^{\text {th }}$ Conference and Congress of the European Association of Sport Sociology in Utrecht/. Gazeta Uniwersytecka UR, 3, 86 .

Cynarski, W.J. (2014b). Polish achievements in the theory of physical education and new directions. Ido Movement for Culture. Journal of Martial Arts Anthropology, 2, 1-14. DOI: 10.14589/ido.14.2.1.

Cynarski, W.J., \& Duriček, M. (2014). Scientific tourism. Self-realisation, dialogue-cultural and sacral dimensions. Ido Movement for Culture. Journal of Martial Arts Anthropology, 4, 39-45. DOI: 10.14589/ido.14.4.5. 
Cynarski, W.J., Obodyński, M., Barabasz, Z., \& Zadarko, E. (2014). Physical culture of students in times of system transformation after 1989 in medical colleges and universities in Poland. Scientific Review of Physical Culture, 2, 130141.

Cynarski, W.J., \& Yu, J.-H. (2011). The Lifestyle of People Practicing the martial Arts - Active, Healthy, and Creative. PanAsian Journal of Sports \& Physical Education, 4, 35-44.

Grzywacz, R., \& Wielgos, K. (2013). The success of the Faculty of Physical Education - for membership of the HEPA Europe. Gazeta Uniwersytecka UR, 5, 53.

IMACSSS (2015, July). Status IMACSSS, Retrieved July 15, 2015, from http://www.imacsss.com.

IPA (2015, July). Status IPA, Retrieved July 15, 2015, from http://www.idokan.pl.

Junger, J. (2009). School physical education and academic sport in the new millennium. In E. Zadarko, \& Z. Barabasz (Eds.), Academic Physical Education. Health, lifestyle and motor abilities (pp. 7-17). Rzeszow: Rzeszow University Press.

Krippendorf, J. (2004). Content Analysis: An Introduction to Its Methodology. Thousand Oaks, CA: Sage.

Lukiewicz, W. (2013). The role of the university sport clubs in the students life in Belarus (years 1985-1997). In W.J. Cynarski, A. Nowakowski, \& S. Zaborniak (Eds.), Szkice z teorii i historii wychowania fizycznego, sportu $i$ turystyki /Sketches of the theory and history of physical education, sport and tourism/ (pp. 97-102). Rzeszow: Rzeszow University Press.

Mayring, P. (2004). Qualitative content analysis. In U. Flick, E. von Kardoff, \& I. Steinke (Eds.), A Companion to Qualitative Research (pp. 266-269). London: Sage.

Moegling, K. (2006). Bildung als Ausweg „des Menschen aus seiner selbstverschuldeten Unmündigkeit” - Zum Bildungsverständnis und zur Konzeption einer zeitgemäßen Sport- und Bewegungspädagogik /Education as a way out "of man from his self-indebted immaturity" - On the understanding of education and the conception of a modern sports and movement pedagogy/. Ido - Ruch dla Kultury / Movement for Culture, 6, 268-275.

Sieber, L., Litwiniuk, A., \& Cynarski, W.J. (2010). Ecological education through the ways of martial arts. Ido - Ruch dla Kultury / Movement for Culture, 1, 53-57.

Uher, I. (2009). Health, well-being and exercise analysis of older population. In W.J. Cynarski, \& S. Cieszkowski (Eds.), Raporty i szkice o kulturze fizycznej i zdrowotnej w perspektywie humanistycznej /Reports and essays on physical and health culture in the perspective of the humanities/ (pp. 168-174). Rzeszow: Rzeszow University Press.

Zeng, H.Z., Cynarski, W.J., \& Lisheng, X. (2013). Martial Arts Anthropology, Participants' Motivation and Behaviours. Martial Arts in Changshu: Participants' Motivation, Practice Times and Health Behaviours. Saarbrücken: Lambert Academic Publishing.

AUTHOR'S ADDRESS: Przemysław Pawelec Committee of Scientific Research

Idokan Poland Association

Towarnickiego $3 \mathrm{~b}$

35-959 Rzeszow, Poland

Email: przemyslaw.pawelec@idokan.pl

Received: 19 September 2015; Accepted: 10 December 2015 